\title{
A CONSTITUCIONALIZAÇÃO DAS PRERROGATIVAS DOS ADVOGADOS E A ATUAÇÃO DA OAB NA VALORIZAÇÃO DA ADVOCACIA E NO COMBATE AO ABUSO DE AUTORIDADE
}

\section{Robson Sabino de Sousa*}

\section{RESUMO}

A Constituição Federal de 1988 reconhece a advocacia como essencial à Justiça. A criminalização da advocacia e as ações contra o patrimônio do advogado muitas vezes são utilizadas para intimidar. Por intermédio de pesquisa bibliográfica e dados decorrentes de notícias jornalísticas e da experiência colhida ao longo de sete anos de existência do Centro de Apoio e Defesa do Advogado e da Advocacia, faz-se uma análise das principais reclamações dos advogados em relação ao Poder Judiciário do Estado do Ceará. Ao final, demonstra-se a importância da OAB na valorização da advocacia, substituindo o advogado no confronto com autoridades.

Palavras-chave: Problemas do Judiciário. Ativismo. Abuso de autoridade. Criminalização da advocacia. Ordem dos Advogados do Brasil.

\section{THE CONSTITUTIONALIZATION OF LAWYER'S PRIVILEGES AND THE OAB'S ACTION IN VALUING ADVOCACY AND COMBATING AUTHORITY ABUSE}

\begin{abstract}
The 1988 Federal Constitution recognizes advocacy as essential to justice. The criminalization of advocacy and actions against the patrimony of the lawyer are often used to intimidate. Through bibliographical and data derived from news reports and the experience gathered during the 7 years of existence of the Center of Support and Defense of the Lawyer and of the Law, an analysis is made of the main complaints of the lawyers in relation to the Judicial Power of the State of Ceará. At the end, it is demonstrated the importance of the OAB in the valuation of the law, replacing the lawyer in the confrontation with authorities.
\end{abstract}

Keywords: Problems of the Judiciary. Activism. Abuse of authority. Criminalization of advocacy. Brazilian Bar Association.

\section{INTRODUÇÃO}

O Estado policialesco instalado no Brasil, motivado por escândalos no Poder Legislativo e Executivo Federal, e que culminaram com um processo de impedimento da Presidente da República e pela descoberta de dezenas de políticos influentes em esquemas gigantescos de

\footnotetext{
*Mestrando em Direito Processual e Desenvolvimento pelo Centro Universitário Christus (Unichristus). Bacharel em Direito pela Universidade de Fortaleza (Unifor). Assessor Jurídico da Ordem dos Advogados do Brasil, secção do Ceará. Membro da Comissão de Defesa das Prerrogativas dos Advogados e Valorização da Advocacia da OAB/CE.

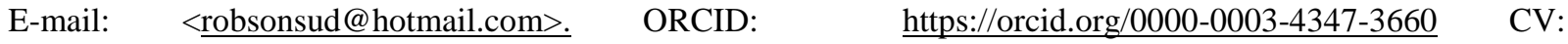
http://lattes.cnpq.br/6972401735950804
}

Rev. de Política Judiciária, Gestão e Administração da Justiça| e-ISSN: 2525-9822 | Porto Alegre | v. 4 | n. 2 | 
corrupção tem servido de justificativa para autoridades reduzirem garantias constitucionais dos réus e dos advogados.

A criminalidade crescente é outro fator que favorece o autoritarismo. Tratando-se de acusados pelo cometimento de qualquer crime, notadamente de corrupção, a população, de modo geral, apoia todo tipo de autoritarismo. Prisões temporárias para averiguações e utilizadas para forçar depoimentos e delações, bem como conduções coercitivas têm se tornado regra. Como poderá o advogado se insurgir contra arbitrariedades sem se cercar de proteção legal? Assim, não apenas a constitucionalização das prerrogativas deve ser reforçada, mas também a criminalização de suas constantes violações, pois somente representações administrativas não se tem mostrado eficientes para coibir os frequentes desrespeitos as prerrogativas.

Existe por parte de algumas autoridades atitudes de criminalização e responsabilização civil da advocacia através de instrumentos que sequer eram utilizados na ditadura. Muitos juízes, promotores e delegados ainda veem nos advogados um inimigo e entrave para realizar seu trabalho, principalmente os que preferem atuar ao arrepio da lei. No exercício de sua profissão, muitos advogados têm suas condutas criminalizadas e respondem principalmente pelo crime de calúnia que a princípio não encontra guarida no Estatuto da Advocacia.

Por meio de pesquisa bibliográfica e de campo, o presente trabalho pretende analisar os requerimentos formuladas pelos advogados à Ordem dos Advogados do Brasil (OAB), seccional do Ceará, identificando os principais problemas do judiciário cearense.

As fontes utilizadas serão livros, artigos de divulgação científica, revistas especializadas e publicações periódicas. Utilizar-se-ão ainda dados coletados entre o período de janeiro de 2010 a junho de 2017 pelo Centro de Apoio e Defesa do Advogado e da Advocacia, na jurisprudência e em matérias jornalísticas, cujos temas estejam relacionados à: Problemas do Judiciário; abuso de autoridade; criminalização da advocacia; OAB.

Ao final, pretende-se analisar a substituição do advogado pela OAB na defesa das prerrogativas e o impacto de uma entidade atuante perante o Poder Judiciário.

\section{O FORTALECIMENTO DO PODER JUDICIÁRIO EM FACE DO DESCRÉDITO DOS REPRESENTANTES DO PODER EXECUTIVO E LEGISLATIVO}

A corrupção é um dos principais problemas brasileiros, tendo recebido atualmente grande destaque perante a opinião pública. Bilhões de reais são gastos anualmente com propinas,

Rev. de Política Judiciária, Gestão e Administração da Justiça| e-ISSN: 2525-9822 | Porto Alegre | v. 4 | n. 2 | p. $32-47$ | Jul/Dez. 2018 
dinheiro público, que poderia ser utilizado em obras de infraestrutura e na melhoria das condições de vida da população. Com frequência, escândalos aparecem na imprensa abalando os poderes da República. Entretanto, a indignação da sociedade é maior quando a corrupção é entre os membros dos Poderes Executivo e Legislativo.

A desonestidade vinda à tona diariamente tem acelerado no Brasil o processo de protagonismo do Poder Judiciário. Especialmente na última década, os "heróis" nacionais têm sido juízes, que saindo do anonimato provocam verdadeiras transformações nos outros poderes.

Aquele que detém o poder tende a abusar, razão pela qual deve ser fracionado e harmônico. Desta forma, tratou Montesquieu, no século XVIII, da separação que deveria haver entre os poderes (MONTESQUIEU, 2000). Entretanto, não há vácuo de poder e diante do enfraquecimento de figuras ligadas ao Executivo e Legislativo, o Judiciário tem ocupado espaços e assumido uma posição privilegiada.

Durante os primeiros anos após a Constituição de 1988, segundo Vianna et al. (2014, p. 48), o Supremo Tribunal Federal (STF) mantinha uma relação muito cuidadosa com os demais poderes, evitando o chamado ativismo judicial. A postura conservadora do Judiciário tem explicação na própria origem aristocrática da magistratura brasileira, pois ser juiz no século XVII, por exemplo, significava ascensão social, em função dos altos custos associados à faculdade em Coimbra. O fenômeno permanece nos dias atuais, uma vez que o ingresso na magistratura exige um longo período de estudo, impedindo que muitos consigam competir em condições de igualdade com aqueles que podem ficar alguns anos, após a conclusão do curso, apenas debruçados sobre os livros. Sobre esta procedência, diz Schwartz (1979, p. 227):

A falta de uma universidade no Brasil e o custo que se incorria para fazer matrícula em Coimbra tirava os brasileiros pobres do processo educacional, de maneira que os magistrados brasileiros ou eram filhos da oligarquia colonial ou dos altos funcionários reais trabalhando no Brasil.

Apesar da maioria dos magistrados não serem de origem humilde, ideologicamente são bastante ecléticos e podem representar uma boa parcela da população. Segundo Gonçalves (2015, p. 291):

\footnotetext{
Há quem entenda que os juízes por constituírem em sua maior parte um seleto grupo, destacado da sociedade e recrutado entre pessoas de classe média ou alta em sua grande maioria, teriam dificuldade em compreender quais os vínculos a serem estabelecidos com a comunidade, já que não representariam a diversidade de segmentos e grupos existentes na população, argumento, que de certo modo, é contrariado por algumas pesquisas de cunho sociológico, realizadas no Brasil, haja vista a inexistência de homogeneidade no perfil do juiz brasileiro.
} 
O destaque do Poder Judiciário vem crescendo não apenas com a judicialização da política e das relações sociais, mas com a aplicação direta dos direitos fundamentais ${ }^{1}$ e com a constitucionalização do direito ${ }^{2}$. Estão os juízes preparados para assumir este protagonismo? De acordo com Gonçalves (2015, p. 299): “A mera aprovação em concurso público, bastante concorrido e com várias etapas, é insuficiente para investir o magistrado neófito das competências, habilidades e atitudes indispensáveis a quem exerce o dificílimo ofício de julgar."

Em um Estado Democrático de Direito não há espaço para atitudes autoritárias, sob pena de prontamente ser repelido. Por estar na frente da batalha jurídica, o advogado acaba, muitas vezes, sendo vítima da falta de urbanidade. Segundo Naline (2013, p. 20-21):

Não pode ser por acaso a pregação do Presidente da OAB, Secção de São Paulo, a cada solenidade de posse, no sentido de reclamar uma maior polidez dos jovens juízes em relação aos advogados. Aquele que foi escolhido quando tantos haviam sido chamados e restaram inaproveitados, tende a se considerar quase-gênio, aquinhoado com atributos inusitados, um ser muito especial.

Deve-se esclarecer que o Poder Judiciário também não está imune e tem sido investigado por atos de corrupção. As denúncias têm se tornado mais frequentes, embora não tenham tanto impacto junto à sociedade como a que ocorre nos outros poderes. No Ceará, por exemplo, a operação "Expresso 150"3 tem colocado em polvorosa alguns juízes, desembargadores e advogados que participavam de um gigantesco esquema de tráfico de influência para soltura de presos. De forma inédita, desembargadores foram conduzidos coercitivamente e tiveram mandados de busca e apreensão contra seus gabinetes e residências. A operação foi tão importante pra o Judiciário que modificou a forma de apreciação de medidas liminares nos plantões judiciais da Justiça Estadual que ficaram mais rígidos.

Os recentes escândalos de corrupção e os possíveis favorecimentos têm trazido ainda para debate a forma como desembargadores e especialmente ministros dos principais Tribunais

\footnotetext{
${ }^{1}$ Segundo Carvalho e Lima (2015, p.18): "Sabe-se que o constituinte brasileiro foi omisso quanto a vinculação expressa dos particulares aos direitos fundamentais, porém, como já foi dito, o $§ 1$, do artigo $5^{\circ}$ da $\mathrm{CF} / 88$ estabelece que 'as normas definidoras dos direitos e garantias individuais têm aplicação imediata', não gerando dúvidas, data máxima vênia, quanto à aplicação de forma direta dos direitos fundamentais às relações privadas."

${ }^{2}$ Para Santos (2011, p. 22): "Desde o final da década de 1980, o sistema judicial começa a apostar na constitucionalização do direito ordinário como estratégia hermenêutica de um garantismo mais ousado dos direitos dos cidadãos, assumindo-se como poder político e colocando-se em confronto com outros poderes, notadamente o executivo, sobretudo em três campos: garantismo dos direitos, controle da legalidade e na judicialização da política."

${ }^{3} \mathrm{~A}$ Operação Expresso 150 investiga um esquema de corrupção no âmbito do Poder Judiciário envolvendo desembargadores, juízes e advogados. A operação recebeu este nome porque cada Habeas Corpus era negociado por até $150.000,00$ Reais (cento e cinquenta mil reais) (POLÍCIA..., 2017).
}

Rev. de Política Judiciária, Gestão e Administração da Justiça| e-ISSN: 2525-9822 | Porto Alegre | v. 4 | n. 2 | 
são escolhidos. Apesar da sabatina feita pelo Senado Federal, a experiência mostra que a escolha feita pelo Presidente da República tem sido referendada ${ }^{4}$, ainda que o candidato não possua as condições de notório saber jurídico ou idoneidade moral. ${ }^{5}$ A escolha política dos desembargadores e ministros vai de encontro à forma de ingresso na magistratura através de um dificílimo concurso $^{6}$. A partir de constantes especulações que ministros teriam sido indicados para beneficiar determinados réus em processos nos Tribunais Superiores, a sociedade brasileira passou a questionar se a forma prevista na Constituição é a ideal para o nosso sistema democrático.

Diante de tanta corrupção e abuso de autoridade, a sociedade tenta se organizar, ainda que pelas redes sociais. A pressão popular vem ganhando força nos últimos anos, e a internet tem contribuído para que o cidadão possa se manifestar.

No entanto, instituições que outrora defenderam a democracia precisam recuperar seu protagonismo nas questões sociais, inclusive a $\mathrm{OAB}$, que ao reafirmar sua principal missão de defender o advogado, e desta forma o Estado Democrático de Direito, de modo que o cidadão não tenha apenas uma Justiça aparente aparente e o resultado seja, como bem assevera Machado (2011, p. 27), "vontade do poderoso, sem observância de qualquer regra que por ventura tenha sido preestabelecida."

\section{A CONSTITUCIONALIZAÇÃO DAS PRERROGATIVAS DOS ADVOGADOS}

Em 1988, surgia uma constituição democrática para o país que acabava de sair de um período ditatorial. A partir daquele momento, a sociedade e as instituições tiveram que começar a se adaptar ao novo paradigma. No entanto, a democratização das instituições e a constitucionalização do direito não aconteceu imediatamente, pois é um processo contínuo que permanece até os dias atuais. A legislação e os entendimentos da jurisprudência foram mudando

\footnotetext{
${ }^{4}$ Em mais de 120 anos de história, o STF rejeitou apenas cinco nomes, todos eles no governo do Presidente Floriano Peixoto (WESTIN, 2015).

5“Art. 101. O Supremo Tribunal Federal compõe-se de onze Ministros, escolhidos dentre cidadãos com mais de trinta e cinco e menos de sessenta e cinco anos de idade, de notável saber jurídico e reputação ilibada. Parágrafo único. Os Ministros do Supremo Tribunal Federal serão nomeados pelo Presidente da República, depois de aprovada a escolha pela maioria absoluta do Senado Federal." (BRASIL, 1988, online).

${ }^{6}$ Gonçalves (2015, p.301) reconhece a necessidade do concurso público para seleção de magistrados, evitando práticas que atentem contra a moralidade e a impessoalidade, embora admita que o concurso acaba por não se revelar apto a selecionar os melhores profissionais, por privilegiar a capacidade de memorização em detrimento dos conteúdos humanísticos e outros conhecimentos como fundamentação, argumentação e raciocínio jurídico.
} 
com o tempo, mas ainda temos leis em vigor que foram feitas à época de regimes autoritários como o Código Penal e de Processo Penal e a Lei de Abuso de Autoridade ${ }^{7}$.

A Constituição de 1988 trouxe, entre suas inovações, a constitucionalização das prerrogativas dos advogados, destacando sua proteção: “Art. 133. O advogado é indispensável à administração da justiça, sendo inviolável por seus atos e manifestações no exercício da profissão, nos limites da lei." (BRASIL, 1988, online). O advogado é parte central na evolução do Estado Democrático de Direito, muitas vezes contrariando interesses de grupos poderosos. Portanto, foi necessário, alçar proteção constitucional a advocacia, para que o defensor pudesse exercer seu ofício com independência e sem temer represálias.

Não apenas a advocacia foi reconhecida constitucionalmente, mas a Ordem dos Advogados do Brasil é citada em diversos dispositivos ${ }^{8}$, transformando-a não apenas em órgão de classe, mas em defensora da Constituição, dos direitos humanos, do Estado Democrático de Direito e do aperfeiçoamento das instituições jurídicas. ${ }^{9}$

No decorrer de três décadas, os direitos foram sendo ampliados e os ramos do direito constitucionalizados $^{10}$, não havendo mais como se falar em direito público e privado ${ }^{11}$ de forma separada. Até mesmo o direito processual tem sido visto sob uma perspectiva constitucional, tendo como finalidade a realização das garantias fundamentais ${ }^{12}$.

\footnotetext{
${ }^{7}$ Código Penal -Decreto-lei no 2.848, de 7 de dezembro de 1940 (BRASIL, 1940).Código de Processo Penal Decreto-lei $\mathrm{n}^{\mathrm{o}}$ 3.689, de 3 de outubro de 1941 (BRASIL, 1941). Lei de abuso de autoridade-Lei $\mathrm{n}^{\circ} 4.898$, de 9 de dezembro de 1965 (BRASIL, 1965).

${ }^{8}$ Dentre as atribuições constitucionais da $\mathrm{OAB}$, estão a participação em todas as fases de concursos públicos para magistrados e promotores de justiça bem como a possibilidade de ingressar com ADIN sobre qualquer tema e não apenas aos ligados ao exercício profissional dos advogados nos termos do artigo 103, VII da CF/88.

9“'Art. 44. A Ordem dos Advogados do Brasil (OAB), serviço público, dotada de personalidade jurídica e forma federativa, tem por finalidade: I - defender a Constituição, a ordem jurídica do Estado democrático de direito, os direitos humanos, a justiça social, e pugnar pela boa aplicação das leis, pela rápida administração da justiça e pelo aperfeiçoamento da cultura e das instituições jurídicas; II - promover, com exclusividade, a representação, a defesa, a seleção e a disciplina dos advogados em toda a República Federativa do Brasil.” (BRASIL, 1994, online).

${ }^{10}$ A Constitucionalização do direito privado implica uma reformulação nas relações privadas, na medida em que os valores liberais relativos à liberdade de contratação, à livre iniciativa e ao direito de propriedade, passam a ser pautados pelo critério da funcionalização do direito. (VENTURI, 2016, p. 9).

${ }^{11}$ Segundo Facchini Neto (2003, p.48): "De qualquer sorte, do ponto de vista jurídico, percebe-se claramente que público e privado tendem a convergir. Tal convergência, aliás, opera nas duas direções, ou seja, cada vez mais o Estado se utiliza de instrumentos jurídicos do direito privado, estabelecendo relações negociais com os particulares, e consequentemente abrindo mão de instrumentos mais autoritários e impositivos (trata-se do fenômeno conhecido como privatização do direito público). Por outro lado, também o direito privado, se desloca em direção ao público, como se percebe na elaboração da categoria dos interesses coletivos e difusos (metaindividuais ou supraindividuais)."

${ }^{12}$ Segundo Baracho (2008), o processo é uma metodologia para a realização dos direitos fundamentais.
} 
Da mesma forma, as prerrogativas da advocacia devem ser vistas sob o prisma constitucional. Não se tratam de privilégios, mas de condições necessárias ao advogado para que possa exercer seu múnus público, tendo como única preocupação a salvaguarda do direito. Onde consta no artigo $7^{\circ}$ na lei 8.906/94 (BRASIL, 1994) a expressão “são direitos do advogado", deve se interpretar como prerrogativas de função que não dizem respeito a pessoa do advogado, mas ao exercício da profissão. ${ }^{13}$

O defensor precisa de garantias para que não seja afligido ${ }^{14}$ com a mesma opressão ${ }^{15}$ sofrida por seu cliente tendo que se dividir na sua autodefesa e na de seu constituinte. Como ranso da ditadura, alguns querem confundir o advogado com o cliente supostamente criminoso ${ }^{16}$, especialmente quando, ao promover a defesa do seu constituinte, aquele é obrigado a se insurgir contra autoridades e pessoas influentes com finalidade de evitar condutas ilegais e antidemocráticas. ${ }^{17}$

\title{
4 O CENTRO DE APOIO E DEFESA DO ADVOGADO E DA ADVOCACIA
}

O objetivo do Centro de Apoio e Defesa do Advogado e da Advocacia é intervir nos casos urgentes e que não possam aguardar o trâmite exigido pela OAB/CE para processar uma reclamação. No sítio eletrônico da OAB/CE encontramos sua finalidade:

\begin{abstract}
O Centro de Apoio e Defesa do Advogado e da Advocacia integra a OAB/CE, e foi criado para oferecer suporte aos advogados que estão sendo tolhidos, naquilo que diz respeito aos direitos e prerrogativas profissionais, minimizando as dificuldades que possam encontrar e garantindo um melhor desempenho na atividade profissional do advogado.O CADAA visa adotar providências necessárias à defesa do advogado e da advocacia, acompanhando, defendendo e assistindo o advogado quando atingido em suas prerrogativas profissionais ou quando prejudicado em seu exercício profissional (ORDEM DOS ADVOGADOS DO ESTADO DO CEARÁ, 2017, online).
\end{abstract}

\footnotetext{
${ }^{13}$ De acordo com os ensinamentos de Ramos (2003, p. 134): "Estes direitos não lhe são conferidos na condição de pessoas físicas, comuns, mas na especial condição de agente publico no exercício de seu mister que já dissemos é um munus público, para que lhe sejam asseguradas perfeitas condições ao pleno exercício profissional, de modo a garantir que seja atendido o interesse público na realização da justiça."

${ }^{14}$ Juiz Sérgio Moro explica ao STF grampo em telefone de escritório de advocacia (MORO..., 2016).

${ }^{15} \mathrm{OAB} / \mathrm{RJ}$ promove desagravo e face da condução coercitiva de advogados do BNDES (GANDRA, 2017).

${ }^{16}$ Uma juíza de Cuiabá sob argumento de que "advogados criminalistas têm conhecimento de fatos que poderão ser manipulados para atrapalhar a instrução criminal" decretou a prisão preventiva de alguns advogados, sustentando que: Além disso, especificamente no caso presente, poderá dificultar as investigações, utilizando-se de suas prerrogativas de advogado, inclusive para obter acesso em autos sigilosos, dados estes que um investigado qualquer jamais obteria (CONSELHO FEDERAL DA ORDEM DOS ADVOGADOS DO BRASIL, 2017).

${ }^{17}$ Conduções devem ser medidas excepcionais utilizadas quando o acusado ou testemunha recusa o chamado da justiça e não como regra. Até o dia 5/3/2016, a operação Lava Jato havia mandado conduzir coercitivamente 117 pessoas (BRANDT; MACEDO; AFFONSO, 2016).
}

Rev. de Política Judiciária, Gestão e Administração da Justiça| e-ISSN: 2525-9822 | Porto Alegre | v. 4 | n. 2 | 
A experiência exitosa do Ceará foi transmitida para o Conselho Federal e outras seccionais que nos últimos anos criaram procuradorias, tendo em vista que a violação das prerrogativas de um advogado atinge, posteriormente, toda à advocacia. De acordo com o Manual de Defesa das Prerrogativas dos Advogados da OAB/CE (ORDEM DOS ADVOGADOS DO ESTADO DO CEARÁ, 2012, p. 31):

\begin{abstract}
A violação das prerrogativas dos advogados, dentre elas, a igualdade em relação àqueles com que venha se relacionar em razão da profissão, não se circunscreve à pessoa do ofendido, mas constitui, sobretudo, uma ofensa a classe e, em última análise, aos direitos fundamentais do cidadão, cuja defesa é promovida pela classe dos advogados, através do desempenho de suas atividades.
\end{abstract}

As principais reclamações dos advogados têm sido quanto às dificuldades impostas por autoridades para o exercício profissional. Para se chegar ao resultado foram analisados 4.589 requerimentos do Centro de Apoio e Defesa do Advogado entre janeiro de 2010 à junho de 2017 e que foram cadastradas no sistema DATAGED - OAB/CE. ${ }^{18}$

Gráfico 1 -Requerimentos ao Centro de Apoio

m não violaçöes de prerrogativas = violações de prerrogativas

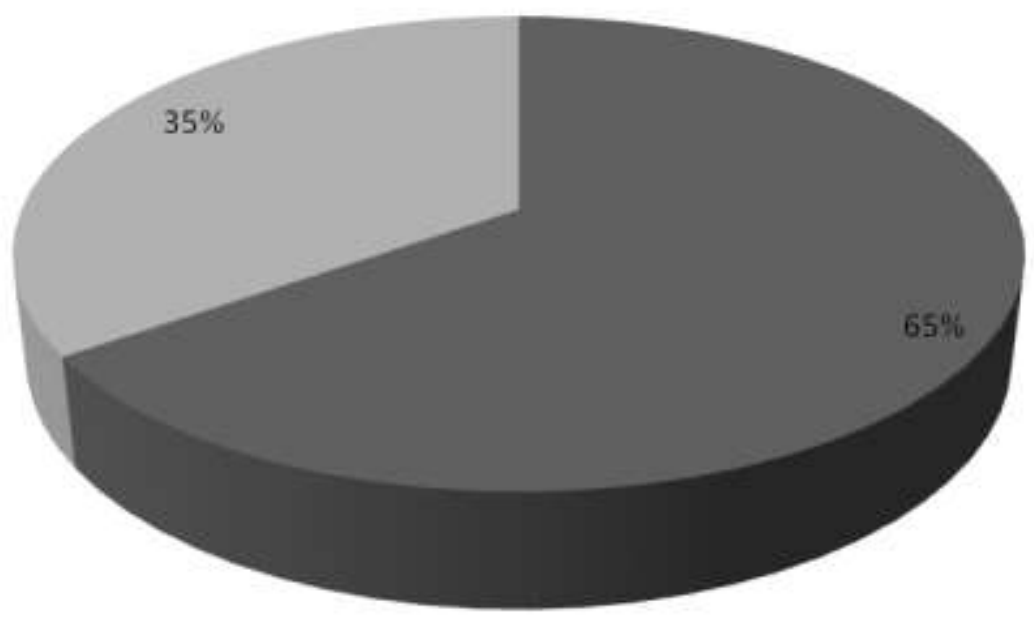

Fonte:dados da pesquisa (2018).

\footnotetext{
${ }^{18}$ Os dados foram coletados através do sistema DATAGED da OAB/CE, por meio de pesquisa por assunto e não corresponde a totalidade de atendimentos do Centro de Apoio e Defesa do Advogado e da Advocacia. Exclui-se da pesquisa: solicitações feitas por meio do plantão telefônico, presenciais ou outros que foram resolvidos e que não ocasionaram abertura de procedimento no sistema interno na OAB/CE (DATAGED).
}

Rev. de Política Judiciária, Gestão e Administração da Justiça| e-ISSN: 2525-9822 | Porto Alegre | v. 4 | n. 2 | 
Do total pesquisado, 2.995 procedimentos ou $65,26 \%$ não correspondem a violações de prerrogativas e foram agrupados da seguinte forma:

Gráfico 2 - Atendimentos não relacionados a violação de prerrogativas

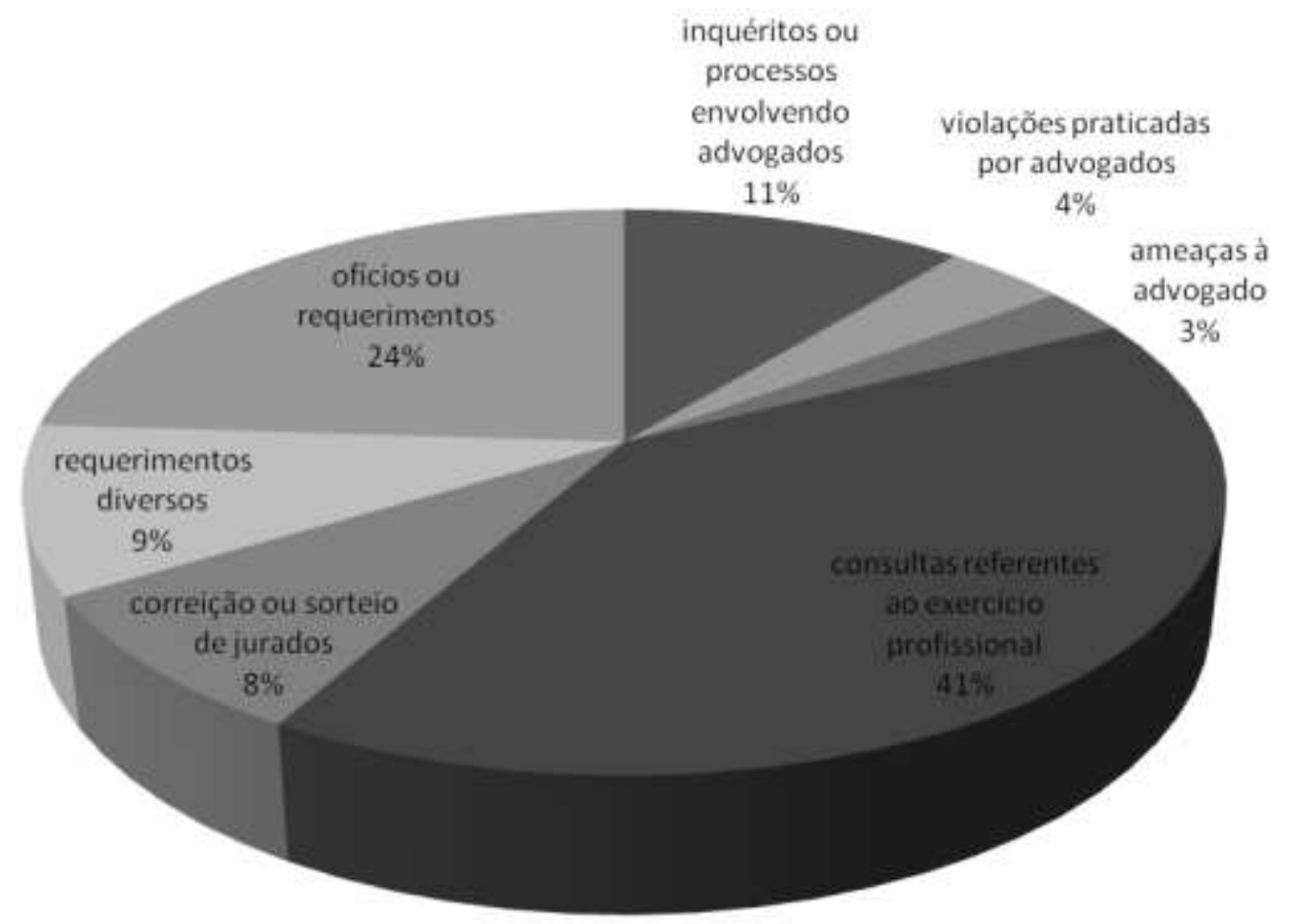

Fonte: dados da pesquisa (2018).

Gráfico 3 -Atendimentos não relacionados à violação de prerrogativas 


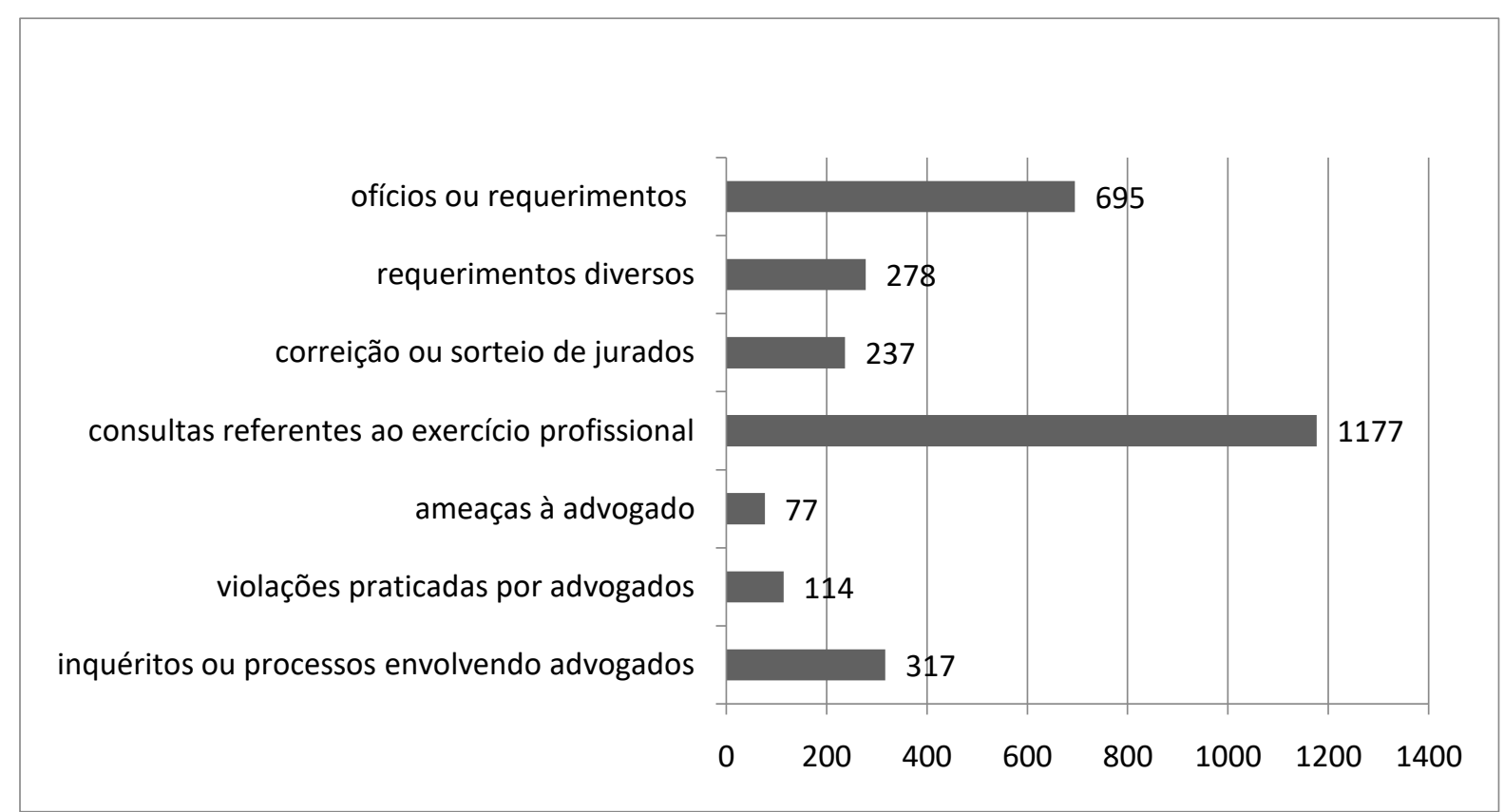

Fonte: dados da pesquisa (2018).

Neste primeiro grupo de requerimentos pesquisados, chama atenção a enorme quantidade de requerimentos para que a $\mathrm{OAB} / \mathrm{CE}$ acompanhasse inquéritos ou processos envolvendo advogados (317), e pedidos de assistência para quando o profissional estava sendo acusado de cometer algum tipo de ilícito civil ou penal (117). Os números demonstram uma crescente responsabilização da advocacia por atos praticados no exercício profissional, e que a princípio estariam abarcados pela imunidade processual.

Os principais crimes que os advogados respondem no exercício da profissão são os contra a honra e por pareceres em licitações de prefeituras do interior. Os casos mais frequentes em que são demandados patrimonialmente, em razão do exercício profissional, são ações por reparação moral em razão de palavras ásperas contra autoridades e partes adversas.

Os demais processos, correspondendo $34,74 \%$ do total, dizem respeito a violações de prerrogativas por autoridades, ou pela falta de estrutura para atendimento do advogado, e foram agrupados em dez principais assuntos:

Gráfico 4 -Violações de prerrogativas 


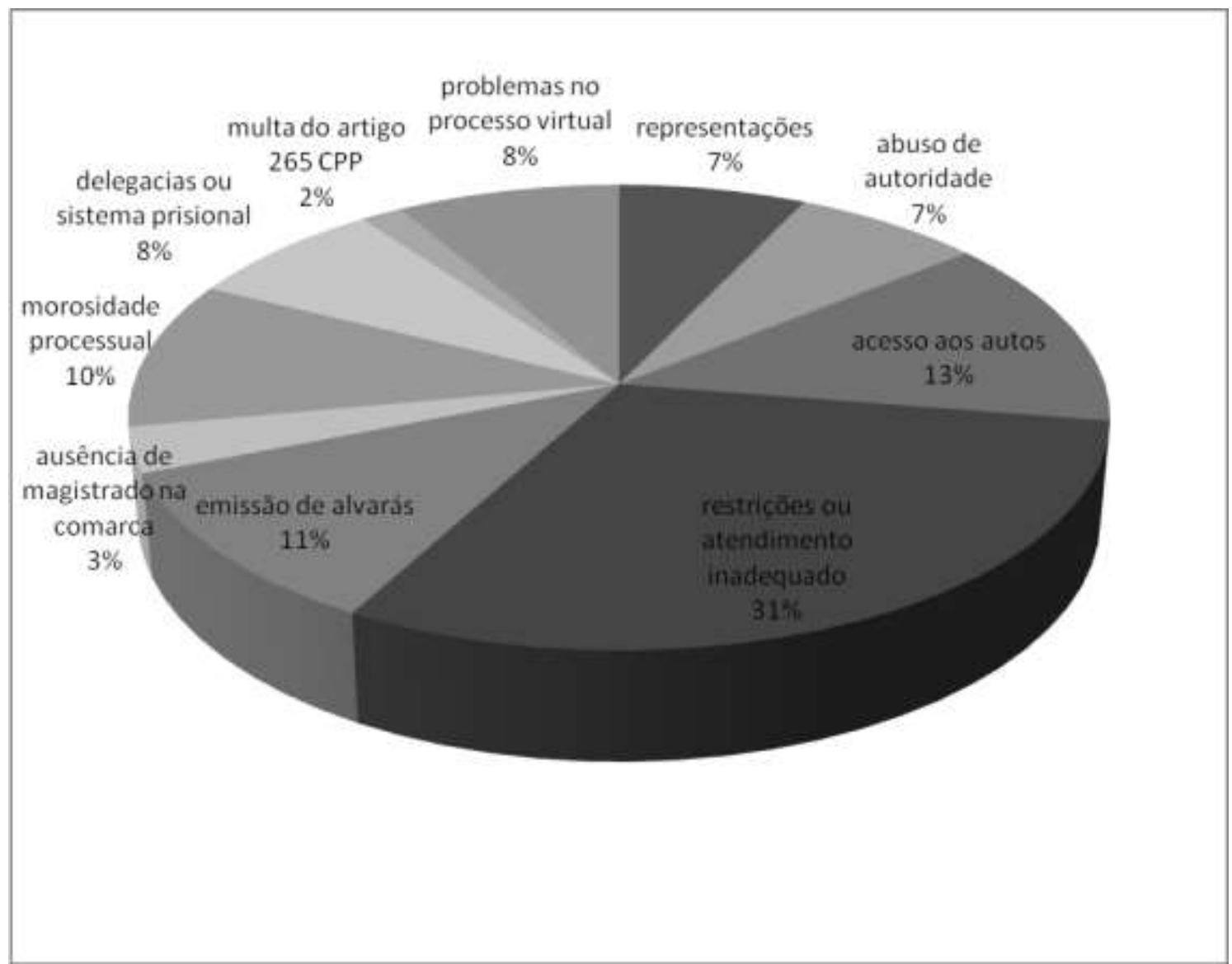

Fonte: dados da pesquisa (2018).

Gráfico 5 -Violações de Prerrogativas

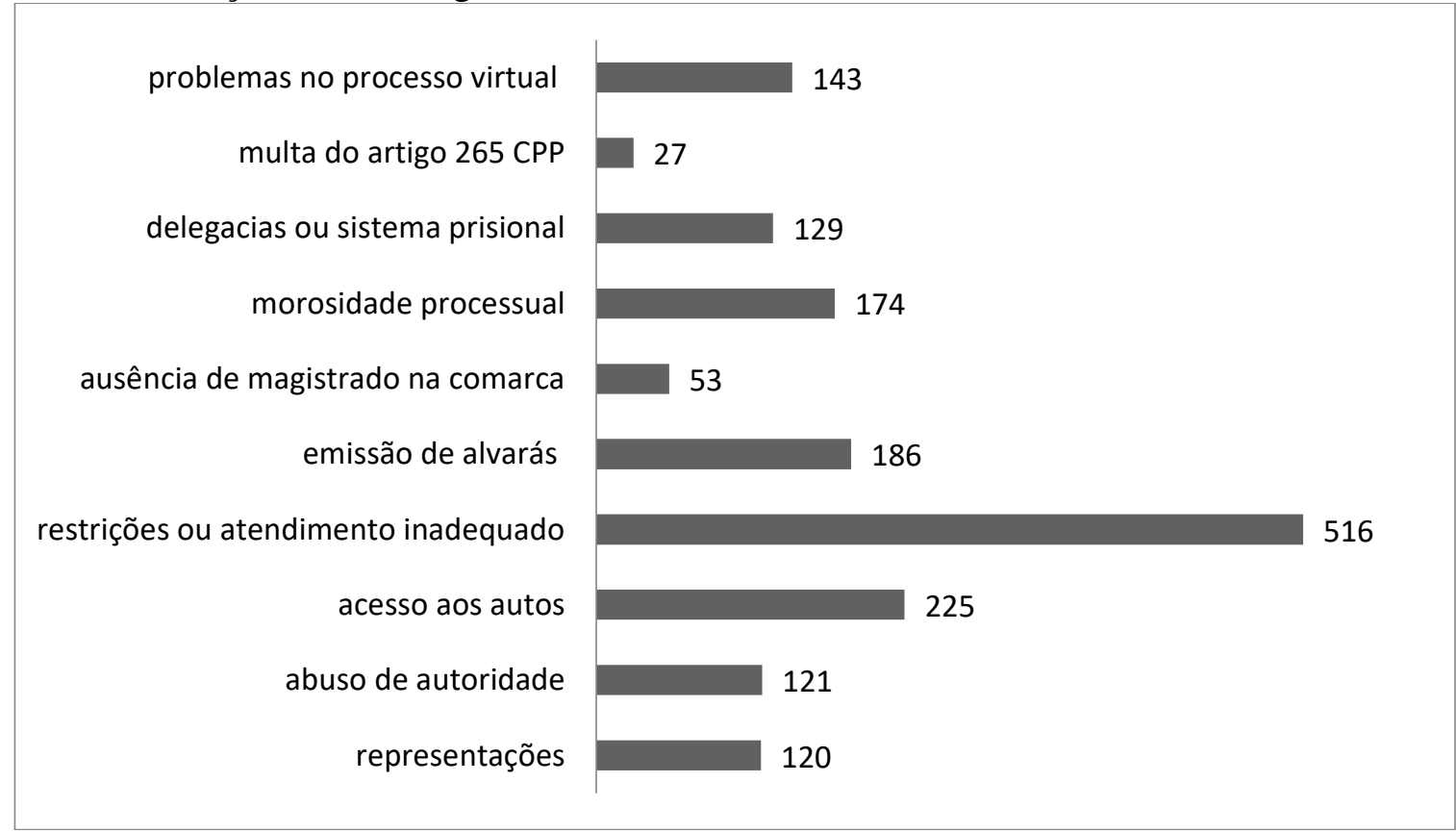

Fonte: dados da pesquisa (2018).

Rev. de Política Judiciária, Gestão e Administração da Justiça| e-ISSN: 2525-9822 | Porto Alegre | v. 4 | n. 2 | p. 32 - 47 | Jul/Dez. 2018 
Neste segundo grupo analisado, ${ }^{19}$ a grande maioria das reclamações é referente a prerrogativas expressas na Lei 8.906/94 (BRASIL, 1994), como inacessibilidade aos autos e negativa dos magistrados em receber o advogado. Uma segunda parte é decorrente da falta de servidores e de estrutura do próprio Poder Judiciário, especialmente na Justiça Estadual do Ceará. Por fim, a interferência nos honorários e na relação entre as partes e seus constituídos também tem sido motivo de inúmeras reclamações.

Em relação ao período analisado, a maior quantidade de reclamações ocorreu nos anos de 2011 e 2012, com 1020 e 765 requerimentos, respectivamente. As principais causas foram a reforma no Fórum de Fortaleza e a virtualização dos processos ${ }^{20}$, demonstrando que a falta de estrutura física adequada é um dos mais fortes entraves para o trabalho do advogado, pois impede ou dificulta o direito de tão somente peticionar.

Quando o problema não é a falta de estrutura, mas o entendimento equivocado referente às prerrogativas dos advogados, a experiência demonstra que a maioria dos procedimentos é logo encerrado, uma visita in loco ou até mesmo uma ligação se mostrou suficiente. Somente quando a autoridade resolve não modificar seu entendimento é que a representação passou a ser considerada, seja por interesse do advogado ou da própria entidade.

\section{CONCLUSÃO}

A profunda mudança de paradigma ocorrida na história do Brasil com o fim do período ditatorial provocou um aperfeiçoamento das instituições, notadamente o Poder Judiciário. Antes de caráter eminentemente autoritário, fruto de um tempo em que as liberdades foram suprimidas, os juízes e a legislação tiveram que se adaptar a esta nova fase da história do Brasil.

À medida que as instituições evoluíram para se acostumar à democracia, os órgãos de controle e o Poder Judiciário passaram a ter um protagonismo, anteriormente inexistente. De fato, o STF, por exemplo, evitou confrontos com os demais poderes durante os primeiros anos da Constituição de 1988. A judicialização da política e das relações sociais, somadas ao ativismo

\footnotetext{
${ }^{19}$ Estes números incluem todas as violações a prerrogativas que se enquadrem nos assuntos analisados e não especificamente no âmbito do Poder Judiciário.

${ }^{20} \mathrm{OAB} / \mathrm{CE}$. OAB-CE cobra resposta imediata do TJCE sobre virtualização de processos no Ceará e reforma do Clóvis Beviláqua (ORDEM DOS ADVOGADOS DO ESTADO DO CEARÁ, 2011).
} 
judicial foram importantes para que o Judiciário assumisse papel fundamental no Estado, frequentemente dando a palavra final sobre determinada matéria oriunda de outros poderes.

Por outro lado, o Poder Executivo e o Legislativo perderam credibilidade perante a sociedade, bem como muitos de seus membros se veem em constantes escândalos de corrupção. Ocupando um vácuo de poder, o Judiciário assumiu para si a missão de resolver muitos problemas que não são de sua competência, como no caso da corrupção.

As denúncias envolvendo os outros poderes também afetam o Judiciário. Ocorre que pelo fato de os juízes não serem eleitos, a opinião pública acaba por não lhes punir com exposição midiática, como acontece com o representante político. Por outro lado, as prerrogativas nunca foram tão violadas, sendo importante entender a sua constitucionalização, assim como ocorre em outras áreas do Direito, como, por exemplo, no Direito Civil.

Nossa democracia ainda é frágil e sofre influências de períodos autoritários, especialmente da legislação oriunda deste período, como o Código Penal e de Processo Penal e a Lei de Abuso de Autoridade. Por esta razão, muitos magistrados acreditam que a advocacia atrapalha o Estado de atingir seus fins e desta forma acabam violando garantias constitucionais do cidadão. A população, abatida pela corrupção e também violência, apoiam em sua maioria e tornam heróis juízes que violam as prerrogativas dos advogados e cerceiam os direitos dos acusados.

A constitucionalização das prerrogativas dos advogados não é apenas uma conquista de uma classe profissional, mas é importante para a sociedade, pois o advogado precisa de meios legais para defender seu cliente com independência. Apesar de parte da legislação não ser democrática, os interpretes do direito devem fazê-lo nos moldes da Constituição.

Um dos principais meios utilizados para calar a advocacia é a adoção de medidas criminais pela autoridade que se sentiu lesada por comentários no bojo de petições e ainda a abertura de ações de reparação por danos morais.

O Estatuto da OAB e o Regulamento Geral obrigam a entidade a assistir o advogado quando este responder criminalmente por conduta que lhe foi atribuída no exercício da profissão, porém é omissa nos casos de reparação civil, onde as condenações podem se verificar em patamares altíssimos.

Diante das constantes violações, a OAB/CE criou em 2010 o Centro de Apoio e Defesa do Advogado, um setor específico para defender o advogado quando tivesse prerrogativas violadas no exercício da profissão. As violações são bastante frequentes e versam desde a estrutura

Rev. de Política Judiciária, Gestão e Administração da Justiça| e-ISSN: 2525-9822 | Porto Alegre | v. 4 | n. 2 | p. $32-47$ | Jul/Dez. 2018 
física e a falta de juízes e servidores, fatores que contribuem para a morosidade. Outras frequentes violações são a inacessibilidade aos autos ainda que não estejam em segredo de justiça e o não atendimento dos advogados.

Percebeu-se na pesquisa de campo, realizada com mais de 4.500 requerimentos, ao longo de quase sete anos, que muitas das violações são facilmente resolvidas, até mesmo por telefone. Porém, no caso de representação disciplinar, a presença da OAB, se faz fundamental, de forma que o advogado individualmente não sofra qualquer tipo de punição.

\section{REFERÊNCIAS}

BARACHO, José Alfredo de Oliveira. Direito Processual Constitucional: aspectos contemporâneos. Belo Horizonte: Editora Fórum, 2008.

BRANDT, Ricardo; MACEDO, Fausto; AFFONSO, Julia. Força-tarefa da Lava Jato critica 'falsa polêmica' sobre condução coercitiva de Lula. Estadão, São Paulo, 5 mar. 2016.

Disponível em: <http://politica.estadao.com.br/blogs/fausto-macedo/forca-tarefa-da-lavajato-critica-falsa-polemica-sobre-conducao-coercitiva-de-lula/>. Acesso em: 28 jun. 2016.

BRASIL. Constituição (1988). Constituição da República Federativa do Brasil de 1988. Promulgada em 5 de outubro de 1988. Presidência da República, Brasília, DF, 5 out. 1988. Disponível em: 〈http://www.planalto.gov.br/ccivil_03/Constituicao/Constituicao.htm〉. Acesso em: 9jun. 2017.

. Poder Executivo. Decreto-Lei $\mathrm{n}^{\circ} 2.848$, de 7 de dezembro de 1940 . Código
Penal.Presidência da República, Brasília, DF, 1940. Disponível em:
<http://www.planalto.gov.br/ccivil_03/decreto-lei/Del2848compilado.htm>. Acesso em: 26 jun.
2017.

. Poder Executivo. Decreto-Lei no 3.689, de 3 de outubro de 1941. Código de

Processo Penal. Presidência da República, Brasília, DF, 1941. Disponível em: <http://www.planalto.gov.br/ccivil_03/decreto-lei/Del3689.htm>. Acesso em: 26 jun. 2017.

. Poder Executivo. Lei n ${ }^{\circ}$ 4.898, de 9 de dezembro de 1965. Regula o Direito de Representação e o processo de ResponsabilidadeAdministrativa Civil e Penal, noscasos de abuso de autoridade. Presidência da República, Brasília, DF, 1965. Disponível em: <http://www.planalto.gov.br/ccivil_03/leis/L4898.htm>. Acesso em: 26 jun. 2017.

Poder Executivo. Lei n 8.906, de 4 de julho de 1994. Dispõesobre o Estatuto da Advocacia e a Ordem dos Advogados do Brasil (OAB). Presidência da República, Brasília, DF, 1994. Disponível em: 〈http://www.planalto.gov.br/ccivil_03/leis/L8906.htm〉. Acesso em:26 jun. 2017.

Rev. de Política Judiciária, Gestão e Administração da Justiça| e-ISSN: 2525-9822 | Porto Alegre | v. 4 | n. 2 | p. $32-47$ | Jul/Dez. 2018 
CARVALHO, Alexander Perazo Nunes de; LIMA Renata Albuquerque Lima. A eficácia horizontal dos direitos fundamentais. Revista Opinião Jurídica, Fortaleza, v. 13, n. 17, p. 11 23, jan./dez. 2015. Disponível em: <http://periodicos.unichristus.edu.br/index.php /opiniaojuridica/article/view/469.>. Acesso em: 14 jun.2017.

CONSELHO FEDERAL DA ORDEM DOS ADVOGADOS DO BRASIL. OAB repudia criminalização da advocacia. 2017. Disponível em: <http://www.oab.org.br/noticia/ 54806/oab-repudia-criminalizacao-da-advocacia $\geq$. Acesso em: 28 jun. 2017.

FACCHINI NETO, Eugênio. Reflexões histórico-evolutivas sobre a constitucionalização do direito privado. In: SARLET, Ingo Wolfgang, et al.Constituicão, direitos fundamentais e direito privado. Porto Alegre: Livraria do Advogado, 2003.

GANDRA, Alana. OAB/RJ critica condução coercitiva de advogados do BNDES. EBC Raio Agencia Nacional, Brasília, 17 maio 2017. Disponível em: <http://radioagencianacional. ebc.com.br/geral/audio/2017-05/oab-rj-critica-conducao-coercitiva-de-advogados-do-bndes $\geq$. Acesso em: 28 jun. 2017.

GONÇALVES, Flávio José Moreira. Políticas públicas para a formação e avaliação de magistrados: a contribuição da educação judicial através das escolas de magistratura. Revista Brasileira de Políticas Públicas, Brasília, v.5, n.3, p. 288-314, jul./dez. 2015.

MACHADO, Hugo de Brito. Curso de Direito Tributário.32.ed.São Paulo: Malheiros, 2011.

MONTESQUIEU. O Espírito das Leis. 2. Ed. São Paulo: Martins Fontes, 2000.

MORO explica ao STF grampo em telefone de advogado de Lula. UOL Notícias, 7 abr. 2016. Disponível em: <https://noticias.uol.com.br/ultimas-noticias/agencia-estado/2016/04/07/morose-justifica-a-teori-sobre-grampo-de-advogado.htm>. Acesso em: 28 jun. 2017.

ORDEM DOS ADVOGADOS DO ESTADO DO CEARÁ. OAB-CE cobra resposta imediata do TJCE sobre virtualização de processos no Ceará e reforma do Clóvis Beviláqua. 2011. Disponível em: <http://oabce.org.br/2011/10/oab-ce-cobra-resposta-imediata-do-tjce-sobrevirtualizao-de-processos-no-cear-e-reforma-do-clvis-bevilqua/>. Acesso em: 26 jun. 2017.

. Manual de defesa das prerrogativas dos advogados. Fortaleza, 2012. Disponível em: 〈http://pt.calameo.com/read/00403659557d77ae382dc . Acesso em: 2 jul. 2017.

Centro de Apoio e defesa do Advogado e da Advocacia. Disponível em: 〈http://oabce.org.br/servicos/cadaa/ $>$. Acesso em: 9 jun. 2017.

POLÍCIA Federal colhe depoimentos no Fórum Clóvis Beviláqua em ação da Operação Expresso 150. G1, Ceará, 13 jun. 2017. Disponível em: <http://g1.globo.com/ceara/ noticia/policia-federal-colhe-depoimentos-no-forum-clovis-bevilaqua-em-acao-da-operacaoexpresso-150.ghtml $\geq$. Acesso em: 26 jun. 2017.

NALINE, José Renato. Prefácio. In: PRADO, Lídia Reis de Almeida. O juiz e a emoção: aspectos da lógica da decisão judicial. 6.ed. São Paulo: LTR, 2013. 
RAMOS, Gisela Gondim. Estatuto da Advocacia: comentários e jurisprudência selecionada. 4. ed. Florianópolis: OAB/SC editora, 2003.

SANTOS, Boaventura de Sousa. Para uma revolução democrática da justiça. 3. ed. São Paulo: Editora Cortez, 2011.

SCHWARTZ, Stuart B. Burocracia e sociedade no Brasil Colonial: a Suprema Corte da Bahia e seus juízes: 1609-1751. São Paulo: Editora Perspectiva, 1979.

VENTURI, Thaís Goveia Pascoaloto. A responsabilidade civil como instrumento de tutela e efetividade dos direitos da pessoa. Civilistica, Rio de Janeiro, v. 5, n. 2, p. 1-23, 2016.

VIANNA, Luiz Werneck et al. A judicialização da política e das relações sociais no Brasil. Rio de Janeiro: Editora Revan, 2014.

WESTIN, Ricardo. Senado já rejeitou médico e general para o STF. Jornal do Senado, Brasília, DF, p. 7, 1 jun. 2015. Disponível em: <https://www12.senado.leg.br/ institucional/arquivo/arquivos-pdf/senado-ja-rejeitou-medico-e-general-para-o-stf $\geq$. Acesso em: 28 jun. 2017. 